This is an electronic reprint of the original article. This reprint may differ from the original in pagination and typographic detail.

Author(s): Zeng, Cheng; Croucher, Stephen M.; Kelly, Stephanie; Chen, Hui

Title: An exploration of organizational assimilation among state-owned, private-owned, and foreign-invested enterprises in China

Year: $\quad 2018$

Version:

Please cite the original version:

Zeng, C., Croucher, S. M., Kelly, S., \& Chen, H. (2018). An exploration of organizational assimilation among state-owned, private-owned, and foreign-invested enterprises in China. Communication Research Reports, 35(1), 58-67. https://doi.org/10.1080/08824096.2017.1366304

All material supplied via JYX is protected by copyright and other intellectual property rights, and duplication or sale of all or part of any of the repository collections is not permitted, except that material may be duplicated by you for your research use or educational purposes in electronic or print form. You must obtain permission for any other use. Electronic or print copies may not be offered, whether for sale or otherwise to anyone who is not an authorised user. 


\begin{abstract}
This study explored organizational assimilation in Chinese organizations. To reflect the Chinese context more accurately, the present study compared employees working in three different kinds of organizations: state-owned enterprises (SOEs), private-owned enterprises (POEs), and foreign-invested enterprises (FIEs). Data collected from 220 full-time employees were analyzed using multiple regression analysis. Regression analyses demonstrated employee's level of organizational assimilation was significantly influenced by organizational type: employees in SOEs reported the highest level and employees in FIEs reported the lowest level of organizational assimilation.

Keywords: Organizational assimilation, Organizational type, China
\end{abstract}




\section{An Exploration of Organizational Assimilation among Stated-Owned, Private-Owned, and Foreign-Invested Enterprises in China}

Despite the official job training offered by an organization, newcomers often experience great uncertainty about formal and informal organizational norms and polices. The socialization process into an organization is often complex, yet crucial for both individuals and organizations because effective socialization helps newcomers be more proactive in getting involved in work groups and fostering positive social networks. Over the last three decades, substantial research has explored the conceptualization and measurement of organizational assimilation (Feldman, 1976; Gailliard, Myers, \& Seibold, 2010; Jablin, 1987; Myers \& Oetzel, 2003; Van Maanen, 1975). However, there are two opportunities emerging from the current body of literature. First, our knowledge of organizational assimilation is derived primarily from Western contexts. This has become increasingly more problematic in today's globalized economy as results from studies conducted in Western settings (primarily the United States) cannot be generalized to different cultural, political, and economic systems. There have been various calls for scholars to go beyond Western settings and test the universality of theories in other contexts (Shenkar \& von Glinow, 1994; Xu, Van de Vliert, \& Van der Vegt, 2005). Second, previous literature on organizational assimilation

has predominantly focused on factors at the individual and relational levels, while influences on the organizational level have received less attention. Various researchers suggest context plays an essential role in newcomers' socialization (Ashforth, Saks, \& Lee, 1998; Bauer, Morrison, \& Callister, 1998; Fisher, 1986).

To address these opportunities, the current study takes place in China, which is a significant part of the world economy and also a representative country of the East with unique cultural, political, and socioeconomic schemes. More specifically, this study sheds light on the influence of organizational ownership type on organizational assimilation in China. Organizations in China can be classified into three categories based on their ownership types: State-owned enterprises (SOEs), Private-owned enterprises (POEs), and Foreign-invested enterprises (FIEs). China is experiencing a revolutionary economic transition with massive restructuring SOEs, rapid emergence of POEs, and a huge influx of foreign investment (Xu et al., 2005). On a macro level, these organizations are treated differently under the national economic plan in terms of tax regulations and loan terms from banks (Xia \& Walker, 2015). In addition, organizations with different ownership types demonstrate substantial differences in structure, organizational culture and values, management practice, employee involvement and participation (Tsui, Hui, \& Xin, 2006; Xin, Tsui, Wang, Zhang, \& Chen, 2002). The current study aims to explore how differences among organizations impact organizational assimilation processes in China.

\section{Organization assimilation}

Organization assimilation refers to the dynamic process by which employees enter, socialize into, and retreat from an organization (Jablin, 2001). Jablin (1987, 2001) developed a linear model of organizational assimilation with three stages: anticipatory socialization, the encounter stage, and the metamorphosis stage. These three stages take place in a sequential order and individuals continue to integrate more into an organization throughout the process. 
However, this model devotes little attention to the role an organization plays in the assimilation process. While focusing on the bi-directional nature of assimilation, Myers and Oetzel (2003) asserted organizational assimilation is essentially a process of an interactive mutual acceptance between newcomers and organizations. To measure the assimilation process, Myers and Oetzel (2003) developed the Organizational Assimilation Index (OAI), which involves six dimensions. Familiarity with others involves making friends and building relationships with supervisors. Acculturation is learning and accepting the organizational culture and rules. Recognition entails one's work competence being recognized as valuable in the organization. Involvement indicates actively seeking to contribute to the organization, such as voluntarily taking on extra work. Job competency refers to knowing how to accomplish one's work well. Role negotiation entails employees negotiating and compromising between their expectations and the expectations of the organization. In revalidating the OAI, Gailliard et al. (2010) recoded "familiarity with others" into "familiarity with supervisors" and added one additional dimension, "familiarity with coworkers."

\section{Chinese organizational types}

Three basic forms of organizations emerged during the economic transition in China: state-owned enterprises (SOEs), private-owned enterprises (POEs), and foreign-invested enterprises (FIEs) (Zhang \& Keh, 2010). China had a socialist economy with almost entirely

SOEs before the open-door policy was adopted in 1978 (Li, Lin, \& Selover, 2014). To improve the performance of SOEs and invite more competition into the economy, a large number of SOEs have been reformed through privatization, corporatization, and industrial restructuring (Liu, 2003). Due to the deep-rooted relationship with the Chinese government, SOEs continue to play a significant role in the Chinese economy and enjoy various advantages provided by the state: financial subsidizing, interest loans, grants of land, favorable resources, monopoly rights and so forth (Li et al., 2014). A wide range of ownership was introduced after the economic reform. Over the last three decades, POEs started to emerge rapidly in all industries and became the most significant contributor to Chinese economic growth. Consequently, POEs began to gain more weight in political and economic policy-making procedures (Tsui et al., 2006). Similarly, after the Chinese Cultural Revolution, foreign investments were able to flow into China as a result of China's new economic policy (Xia \& Walker, 2015). With ever-increasing economic importance and potential, China has received the largest amount of foreign direct investment among all developing countries (Zhang \& Keh, 2010). Under the Chinese market policy, most of the foreign investment is made into enterprises with complete foreign ownership, which contributes to almost one fifth of China's GDP (Kettunen, 2014). Many of these FIEs with powerful multinational backgrounds have become strong competitors to domestic firms in China (Tsui et al., 2006).

Organizations with different ownership structures also differ significantly in terms of productivity, firm growth, organizational culture, and employee attitudes (Tsui et al., 2006). SOEs, profoundly influenced by traditional Chinese cultural values and political ideologies, have a reputation for being particularly more hierarchical and bureaucratic (Liu 2003). As for POEs, China has 7.4 million private enterprises, and family business makes up $85.4 \%$ of 
them (Cai, 2015). In these family-run firms, the managerial structure is largely based on the family and kinship status (Tsui, Bian, \& Cheng, 2006). Many FIEs established in China, which are overseas ventures of MNEs, prefer to adopt Western management rules and organizational structures (Gamble, 2000). Consequently, these differences among three organization types may impact organizational member's assimilation process. Therefore, the following research question was proposed:

$R Q$ : To what extent will organization type influence organizational assimilation in China?

\section{Sample}

\section{Method}

A sample of 219 employees in China participated in this study. The participants were recruited through previously established social networks and with the assistance of universities/colleges who also contacted companies in China. The survey was collected in Beijing, Tianjin, Shanghai, and Guangzhou, cities with more liberal, complex markets that host a variety of organizational types (Holmes, 2017). Participants did not receive financial incentive for participation. Participants ranged in age from 18 to $57(M=29.28, S D=8.47)$. Men made up 45.2\% $(n=99)$ of the sample while women accounted for $54.8 \%(n=120)$. The sample's educational level was diverse: $39.3 \%(n=86)$ high school, $34.7 \%(n=76)$ two-years of college, $8.2 \%(n=18)$ 4-year Bachelor degree or equivalent, $10.0 \%(n=22)$ some graduate education, and 7.8\% $(n=17)$ completed graduate degree. The participants' organizational tenure varied extensively: $19.6 \%(n=43)$ less than a year, $19.2 \%(n=42) 1-2$ years, $28.3 \%(n=62) 3-5$ years, $16.0 \%(n=35) 6-10$ years, $8.2 \%(n=18) 11-15$ years, $6.8 \%$ $(n=15) 16-20$ years, and $1.8 \%(n=4)$ had more than 20 years. Employees organizational type broke down as follows: SOEs $21.9 \%(n=48)$, POEs $35.6 \%(n=78)$, and FIEs $42.5 \%(n$ $=93$ ).

\section{Instrumentation}

Organizational assimilation scale. Myers and Oetzel's (2003) 20-item

Organizational Assimilation Index (OAI) was used to assess the extent to which individuals felt assimilated into an organization. All items are measured on a 5-point Likert scale that ranges from (1) strongly disagree to (5) strongly agree. The survey was originally prepared in English and then translated into Chinese by native bilingual speakers and then independently translated back into English. The reliability of the translation was $(\kappa=.82)$.

A confirmatory factor analysis (CFA) was performed on the measure to ensure that items retained meaning across culturs and languages. The initial fit statistics indicated inadequate fit: $\mathrm{GFI}=.49$, RMSEA $=.25, \chi^{2}(164, N=219)=2474.06, p<.001$. As such, items that caused a high amount of residual error or had low factor loadings were removed from the measure. In the end, six items were retained: two in familiarity with others, two from recognition, and the original role negotiation items. Final fit statistics for this measure were: $\mathrm{GFI}=.99$; RMSEA $=.05$; and $\chi^{2}(6, N=216)=9.33, p=.17$. The reliability scores for the retained dimensions were: familiarity with others $\alpha=.95$, recognition $\alpha=.90$, and role negotiation $\alpha=.68$. 


\section{Analysis and Results}

To answer $R Q$, three multiple regression models were constructed, with two models generated. In model 1, organizational tenure was entered as a control variable. In model 2, SOEs and FIEs were added to the model. Dummy variables were created for organization types with POEs serving as the reference group. In all three models, the second models were significant improvements over the first models, thus model 2 was retained for final analysis. See the changes of $R^{2}$ and $F$ in Table 1 . The results revealed SOEs (as opposed to POEs) had a positive effect on all three dimensions of organizational assimilation: $(b=.38, p<.001)$ familiarity with supervisors, $(b=.38, p<.001)$ recognition, and $(b=.40, p<.001)$ role negotiation. Furthermore, FIEs (as opposed to POEs) had a negative effect on five dimensions of organizational assimilation: $(b=-.18, p<.001)$ familiarity with supervisors, $(b$ $=-.23, p<.001)$ recognition, and $(b=-.20, p<.001)$ role negotiation. VIFs in this study ranged from 1.08 to 1.36 , which warrant a low concern for multicollinearity. Durbin-Watson values in the current study ranged from 1.00 to 1.26 , which warrant a low concern for autocorrelation. The observed $R^{2}$ adj in three multiple regression models are respectively.24, .26 , and .28 .

\section{Insert Table 1 here}

\section{Discussion}

This aim of this study was to examine the influence of organization type on organizational assimilation in China. Regression analysis revealed, as opposed to those in POEs, employees in SOEs reported higher levels organizational assimilation. Under the socialist economic regime, SOEs were historically government intended instead of market oriented (Li et al., 2014). As a result, the personnel management in SOEs was to help implement the national recruitment plans and employment decisions were mostly made by the government instead of SOEs themselves (Zhu, 1998). Before the open door policy was adopted in China 1978, employees neither had the freedom to choose where to work nor to switch between organizations. On the other hand, SOEs did not have the authority to dismiss or demote employees either (Lu, 1989). Thus, possessing a position in SOEs was famously known as having the "iron-rice bowl", which represents a job for life and steady income and benefits (Tsui et al., 2006). Following the government reforms, the employment contract system was widely introduced in SOEs to alleviate the overstaffed system and enhance productivities (Hassard, Morris, Sheehan, \& Yuxin, 2006). Although evident improvement in human resource management in SOEs has been witnessed over the last two decades, these reforms have been criticized as being slow and lacking depth (Jefferson \& Rawski, 1994; Li et al., 2014). Under social and political pressures, many SOEs are often forced to keep surplus employees and thus continue to serve as social and economic safe havens for their employees (O’Connor, Deng, \& Tan, 2011). It is common in modern China that workers still expect lifelong employment in the SOEs (Wang, 2004). Thus, it is more likely for newcomers in SOEs to have higher motivation to assimilate upon arrival as they may end up working in the same organization for the rest of their lives. On the other hand, POEs generally have shorter life spans compared to SOEs often due to tight budgets, changing policies, and 
competitive markets (Perkins, 1994). In this sense, the uncertainty of employment is high in POEs and employees may hesitate to fully assimilate into a POE.

As opposed to those in POEs, employees in FIEs reported lower levels of organizational assimilation. Chinese employees have traditionally demonstrated higher levels of organizational loyalty and commitment because organizations are often regarded as "families." Managers in Chinese organizations tend to adopt a paternalistic leadership style by representing the father figure and exhibiting benevolence to employees in return for their loyalty (Sheer, 2013). This could be particularly true for POEs, which are mostly composed of family businesses. On the other hand, FIEs with direct connections to foreign companies often adopt non-Chinese management thoughts and practices (Wang, 2008). Thus, the idea that "organization is family" might be less promoted in FIEs, which ultimately contributes to the low organizational assimilation among employees in FIEs. Another possible explanation for low organizational assimilation in FIEs could be linked with their high turnover rates. Compared to SOEs and POEs, FIEs in China suffer from particularly high employee turnover, 14\% (Fan, 2006; Wang, 2008). FIEs in China tend to focus on cultivating elite employees with competitive salary packages and promotion opportunities (Wang, 2004). However, rank-and-file employees without special education or skills are often seen as replaceable and receive little favorable resources. Annual turnover rates are commonly more than $30 \%$ among low-skilled workers (Beamish, 2006). It is hardly surprising non-elite employees, the majority of the workforce, are disheartened to accept the gap in employee treatment and genuinely want to assimilate into the organization. Moreover, due to the uncertainty associated with the high turnover rate in FIEs, employees are less likely to invest in establishing meaningful and long-term relationships with other organizational members. As interpersonal networks are seen as the primary organization-member engagement (Gamble \& Huang, 2008), Chinese employees may be reluctant to become an integral part of the organization when they are less socially connected with others.

One intention of this study was to test original version of OAI in a Chinese setting. As this scale has never been used in the Chines language, nor tested in the Chinese context, this study explored the 2003 version of the scale in China. Three dimensions of OAI retained in this study were: supervisor familiarity, recognition, and role negotiation and the excluded dimensions were acculturation, involvement, and job competence. Conceptually, the retained dimensions are more supervisor related, while the excluded dimensions are more organization related. China is known as a relationship-oriented society. It is highly possible that the process of organizational assimilation in China is more linked with developing subordinate-supervisor relationship than embracing the organizational culture. In a study exploring organizational commitment in China, Chen, Tsui, Farh (2002) reported personal loyalty to supervisor is more valued than institutional loyalty in Chinese organizations. Many Chinese leaders classify their subordinates into in-group or out-group members based on employee's personal loyalty to the leaders (Cheng, 1995). Thus, organizational assimilation, the process of becoming an in-group member in the organization, could be more strongly associated with interpersonal relationships than the organization per se.

\section{Limitations and future directions}


Although this study provided insights into how organizational constructs function in a different setting, limitations of this study are apparent. Most of the data was collected from major urban cites situated in the eastern coastal area of China. Therefore, to generalize the results of this study to other parts of China warrants caution. Another considerable limitation is the current study relied on self-report measures, which may create issues of social desirability that limit the reliability of the data (Podsakoff \& Organ, 1986). Three out of six dimensions of OAI were dropped in the current study. Organizational scales developed in a Western context might be limiting when used in Chinese organizations (Chen et al., 2002; Shenkar, \& von Glinow, 1994). This study supports this claim, and further encourages more cross-cultural validation studies to test the universality of the existing scales.

\section{Conclusion}

To build on the previous literature, predominantly conducted in the US, this study sheds light on organizational assimilation among Chinese organizations with different ownership types. As revealed in this study, Chinese organizational type has a significant influence on the process of organizational assimilation: employees in SOEs reported the highest level and employees in FIEs reported the lowest level of organizational assimilation. The perception of job security might be a direct factor contributing to the differences in organization assimilation. Employees are more likely to assimilate into SOEs that often offer long-term employment and unenthusiastic to socialize into FIEs which typically suffer from high turnover rates. An emphasis on retaining employees and increasing organizational loyalty could be a step for FIEs to become more competitive in the market. 


\section{References}

Ashforth, B., Saks, A. M., \& Lee, R. T. (1998). Socialization and newcomer adjustment: The role of organizational context. Human Relations, 51, 897-926.

Bauer, T. N., Morrison, E. W., \& Callister, R. R. (1998). Organizational socialization: A review and directions for future research. Research in Personnel and Human Resource Management, 16, 149-214

Beamish, P., W. (2006). The high cost of cheap Chinese labor. Harvard Business Review, 6, Retrieved from: https://hbr.org/2006/06/the-high-cost-of-cheap-chinese-labor

Cai, P. (2015). China's new economic crisis: Keeping the family business. The Asialink Essays 2015, 7. Retrieved from:

http://asialink.unimelb.edu.au/_data/assets/pdf file/0020/2034137/Chinas-New-Eco nomic-Crisis.pdf

Chen, Z. X., Tsui, A. S.\& Farh, J. L.(2002).Loyalty to supervisor vs. organizational commitment: Relationships to employee performance in China. Journal of Occupational and Organizational Psychology, 7, 339-356.

Cheng, B. S. (1995). Chinese CEO's employee categorization and managerial behavior. Paper presented at the Symposium on Indigenous Bebavior in Effective Management and Organizations, sponsored by the Intemational Association of Applied Psychology, Guangzhou, China.

Fan, K. (2006). How can multinational corporations retain their employees in China?. Ithaca, NY: Cornell University, School of Industrial and Labor Relations, Center for Advanced Human Resource Studies. Retrieved from: http://digitalcommons.ilr.cornell.edu/cahrswp/407/

Feldman, D. C. (1976). A contingency theory of socialization. Administrative Science Quarterly, 21, 433-452. doi:10.2307=2391853

Fisher, C. D. (1986). Organizational socialization: An integrative review. In K. M. Rowland \& G. Ferris (Eds.), Research in personnel and human resource management (pp. 101-145). Greenwich, CT: JAI Press.

Gailliard, B. M., Myers, K. K., \& Seibold, D. R. (2010). Organizational assimilation: A multidimensional reconceptualization and measure. Management Communication Quarterly, 24, 552-578,

Gamble, J. (2000). Localizing management in foreign-invested enterprises in China: Practical, cultural, and strategic perspectives. International Journal of Human Resource Management, 11, 883-903.

Gamble, J., \& Huang, Q. (2008). Organizational commitment of Chinese employees in foreign-invested firms. International Journal Of Human Resource Management, 19, 896-915. doi:10.1080/09585190801993893

Hassard, J., Morris, J., Sheehan, J., \& Yuxin, X. (2006). Downsizing the danwei: Chinese state-enterprise reform and the surplus labour question. International Journal of Human Resource Management, 17, 1441-1455.

Holmes, F. (2017, April 21). China's new special economic zone evokes memories of Shenzhen. Forbes. Retrieved from: 
https://www.forbes.com/sites/greatspeculations/2017/04/21/chinas-new-sp

ecial-economic-zone-evokes-memories-of-shenzhen/\#19a30d9376f2

Jablin, F. M. (1987). Organizational entry, assimilation, and exit. In F. M. Jablin,

L. L. Putnam, K. H. Roberts, \& L. W. Porter (Eds.), Handbook of organizational communication (pp. 679-740). Newbury Park, CA: Sage.

Jablin, F. M. (2001). Organizational entry, assimilation, and disengagement/exit.

In F. M. Jablin \& L. L. Putnam (Eds.), The new handbook of organizational communication: Advances in theory, research, and methods (pp. 732-818). Thousand Oaks, CA: Sage.

Jefferson, G., \& Rawski, T. (1994). Enterprise reform in Chinese industry. Journal of Economic Perspectives, 8, 47-70.

Kettunen, E. (2014). China's policy environment toward foreign companies: implications to high-tech sectors. AI \& Society, 29, 403-413.

Li, S., Lin, Y., C., \& Selover, D. D. (2014). Chinese state-owned enterprises: Are they inefficient? Chinese Economy, 47, 81-115.

Liu, S. (2003). Cultures within culture: Unity and diversity of two generations of employees in state-owned enterprises. Human Relations, 56, 387-417.

Lu, F. (1989). Danwei - a special form of social organization. Social Sciences in China, 10, 100-122.

Myers, K. K., \& Oetzel, J. G. (2003). Exploring the dimensions of organizational

assimilation: Creating and validating a measure. Communication Quarterly, 51, 438-457.

O’Connor, N. G., Deng, F. J., \& Tan, J. (2011). The impact of political constraints and formal incentive systems on the performance of Chinese State-owned enterprises. Pacific Accounting Review, 23, 6-33.

Perkins, D. (1994). Completing China's move to the market. Journal of Economic Perspectives, 8, 23-46.

Podsakoff, P. M., \& Organ, D. W. (1986). Self-reports in organizational research: Problems and prospects. Journal of Management, 12, 531-544.

doi: $10.1177=014920638601200408$

Sheer, V. C. (2013). In search of Chinese paternalistic leadership: Conflicting evidence from samples of mainland china and Hong Kong's small family businesses. Management Communication Quarterly, 27, 34-60. doi:10.1177/0893318912458212

Shenkar, O., \& von Glinow, M. A. (1994). Paradoxes of organizational theory and research: Using the case of China to illustrate national contingency. Management Science, 40, 56-71.

Tsui, A. S., Bian, Y., \& Cheng, L. (2006). China's domestic private firms: Multidisciplinary perspectives on management and performance. Armonk, NY: M.E. Sharpe.

Tsui, A. S., Hui, W., \& Xin, K. R. (2006). Organizational culture in China: An analysis of culture dimensions and culture types. Management and Organization Review, 2, 345-376.

Van Maanen, J. (1975). Breaking in: Socialization to work. In R. Dubin (Ed.), Handbook of work, organization, and society (pp. 67-120). Chicago, IL: Rand McNally. 
Wang, Y. (2004). Observations on the organizational commitment of Chinese employees: Comparative studies of state-owned enterprises and foreign-invested enterprises. International Journal of Human Resource Management, 15, 649-669.

Wang, Y. (2008). Emotional bonds with supervisor and co-workers: Relationship to organizational commitment in China's foreign-invested companies. International Journal of Human Resource Management, 19, 916-931. doi:10.1080/09585190801993901

Xia, F., \& Walker, G. (2015). How much does owner type matter for firm performance? Manufacturing firms in China 1998-2007. Strategic Management Journal, 36, 576-585.

Xin, K. R., Tsui, A. S., Wang, H., Zhang, Z., \& Chen, W. (2002). Corporate culture in state-owned enterprises: An inductive analysis of dimensions and influences. In S., A., Tsui \& Lau, C., W. (Eds). The Management of Enterprises in the People's Republic of China, (pp 415-443).New York, NY: Springer.

Xu, H., Van de Vliert, E., \& Van der Vegt, G. (2005). Breaking the silence culture: Stimulation of participation and employee opinion withholding cross-nationally. Management and Organization Review, 1, 459-482.

Zhang, J. \& Keh, H. (2010). Interorganizational exchanges in China: Organizational forms and governance mechanisms. Management \& Organization Review, 6, 123-147. doi:10.1111/j.1740-8784.2009.00148.x

Zhu, C. J. (1998). Human resource development in China during the transition to a new economic system. Asia Pacific Journal of Human Resources, 35, 19-44. 
Table 1

\begin{tabular}{|c|c|c|c|c|c|c|}
\hline \multicolumn{7}{|l|}{ Supervisor familiarity } \\
\hline & \multicolumn{2}{|c|}{ Model 1} & \multicolumn{4}{|c|}{ Model 2} \\
\hline & & $p$ & & $p$ & $V I F$ & Durbin-Watson \\
\hline Intercept & 2.39 & & 2.33 & & & \\
\hline Organizational Tenure & .11 & .10 & $.12 *$ & .05 & 1.06 & \\
\hline State & & & $.38 * * *$ & $<.001$ & 1.30 & \\
\hline Foreign & & & $-.18 * *$ & .01 & 1.33 & \\
\hline$R^{2}$ & .01 & & .25 & & & \\
\hline \multirow[t]{2}{*}{$R^{2}$ adj } & .01 & & .24 & & & \\
\hline & & & & & & 1.50 \\
\hline \multicolumn{7}{|l|}{ Recognition } \\
\hline & \multicolumn{2}{|c|}{ Model 1} & \multicolumn{4}{|c|}{ Model 2} \\
\hline State & & & $.38 * * *$ & $<.001$ & 1.30 & \\
\hline Foreign & & & $-.23 * *$ & .01 & 1.33 & \\
\hline$F$ & .77 & .38 & $26.92 * * *$ & $<.001$ & & \\
\hline$\Delta F$ & & & $39.85 * * *$ & $<.001$ & & \\
\hline$R^{2}$ & .00 & & .27 & & & \\
\hline \multirow{2}{*}{$R^{2}{ }_{a d j}$} & .00 & & .26 & & & \\
\hline & & & & & & 1.43 \\
\hline
\end{tabular}




\begin{tabular}{|c|c|c|c|c|c|c|}
\hline \multicolumn{7}{|l|}{ Role Negotiation } \\
\hline & \multicolumn{2}{|c|}{ Model 1} & \multicolumn{4}{|c|}{ Model 2} \\
\hline & & $p$ & & $p$ & $V I F$ & Durbin-Watson \\
\hline Intercept & 2.32 & & 2.28 & & & \\
\hline Organizational Tenure & .12 & .07 & $.13 *$ & .03 & 1.06 & \\
\hline State & & & $.40 * * *$ & $<.001$ & 1.30 & \\
\hline Foreign & & & $-.20 * *$ & $<.001$ & 1.33 & \\
\hline$R^{2}$ & .02 & & .29 & & & \\
\hline \multirow[t]{2}{*}{$R_{a d j}^{2}$} & .01 & & .28 & & & \\
\hline & & & & & & 1.53 \\
\hline
\end{tabular}

